\title{
STUDY OF ADJUSTMENT IN PATIENTS WITH INVOLUNTARY MOVEMENT DISORDERS
}

\author{
Rajendhar Soorineedu1, Manoj Kumar P2, Krishna Sahithi J3, Dasika Sreekeerthi ${ }^{4}$
}

${ }^{1}$ Senior Resident, Department of Psychiatry, GMC, Nizamabad.

${ }^{2}$ Senior Resident, Department of Psychiatry, GMC, Nizamabad.

${ }^{3}$ Assistant Professor, Department of Psychiatry, KIMS, Hyderabad.

${ }^{4}$ Senior Resident, Department of Psychiatry, OMC, Hyderabad.

\section{ABSTRACT}

\section{BACKGROUND}

Adjustment disorder is a short-term maladaptive reaction to a psychosocial stressor. The reaction is more severe than would normally be expected and can result in significant impairment in social, occupational or academic functioning.

\section{MATERIALS AND METHODS}

This descriptive comparative study was conducted on patients with involuntary movements, categorised on basis of aetiology into involuntary movements due to psychotropic medication and involuntary movements due to neurological disorders. After consent, socio-demographic data was obtained. Instrumental daily activity living scale, work and social adjustment scale, general health questionnaire and abnormal involuntary movement scale were administered for all the patients to find out other related factors.

\section{RESULTS}

Patients with involuntary movements developed due to psychotropic medication has mean score of 2.70 on IADL and 28 on WSAS. Patients with involuntary movements developed due to neurological disorders, not due to psychotropic medication usage has mean score of 2.60 on IADL and 26 on WSAS.

\section{CONCLUSION}

The patients with involuntary movements were dependent. Their functioning was less and they had problems in adjusting to work and social situations, and had psychological disturbances. Both groups have adjustment problems and are strongly correlated with severity of involuntary movements than aetiology.

\section{KEYWORDS}

Movement Disorder, Adjustment Disorder, WSAS, IADL.

HOW TO CITE THIS ARTICLE: Soorineedu R, Kumar MP, Sahithi KJ, et al. Study of adjustment in patients with involuntary movement disorders. J. Evolution Med. Dent. Sci. 2017;6(87):6005-6010, DOI: 10.14260/jemds/2017/1306

\section{BACKGROUND}

Movement disorders are neurological conditions that affect the speed, fluency, quality and ease of movement. Abnormal fluency or speed of movement (Dyskinesia) may involve excessive or involuntary movement (Hyperkinesia) or slowed or absent voluntary movement (Hypokinesia).(1)

Adjustment disorder is a short-term maladaptive reaction to a psychosocial stressor which is expected to remit soon after stressor ceases, or if it persists a new level of adaptation is achieved.

Many studies have documented adjustment associated with a wide variety of chronic health conditions in the past few decades, particularly in mental health, epilepsy, leprosy, HIV/ AIDS and other chronic, disabling conditions. We could not find any study which looked at adjustment in patients with involuntary movement disorders, particularly with a mental illness and psychotropic medication usage background.

'Financial or Other Competing Interest': None.

Submission 09-10-2017, Peer Review 20-10-2017,

Acceptance 23-10-2017, Published 30-10-2017.

Corresponding Author:

Dr. Rajendhar Soorineedu,

Prashanth Neuropsychiatric Hospital,

Pochamma Gally, Nizamabad-503001,

Telangana.

E-mail: rajsoorineedu@gmail.com

DOI: $10.14260 /$ jemds $/ 2017 / 1306$

\section{(c) $(1) \ominus$}

\author{
Aim of the Study \\ To study psychosocial adjustments to involuntary \\ movements.
}

Objectives

1) To study psychosocial adjustments in patients with involuntary movement disorders.

2) To assess the distress, difficulties and effect on activities of daily living in patients with involuntary movement disorders.

\section{Hypothesis}

Null Hypothesis

There is no psychosocial adjustment problems associated with involuntary movements.

\section{MATERIALS AND METHODS}

Study was conducted in Department of Psychiatry, Institute of Mental Health, Hyderabad, a tertiary care psychiatric facility. This is a 600-bedded hospital in Osmania General Hospital, Hyderabad.

\section{Sample}

Patients with involuntary movements are included in the study.

\section{Study Design}

A descriptive comparative study was done in Institute of Mental Health and Osmania General Hospital, Hyderabad. 
Patients who came with involuntary movements on an outpatient basis to the Department of Neurology in Osmania General Hospital and Psychiatry in Institute of Mental Health were taken into consideration and were recruited based on purposive sampling on the following criteria.

\section{Inclusion Criteria}

1) Those who give informed consent.

2) Either the involuntary movements should be related to usage of psychotropic medication or they should be part of involuntary movement disorders.

3) Age above 18 years.

\section{Exclusion Criteria}

1) Patients with diagnosis of dementia.

2) Where there is involuntary movement disorder along with a history of psychotropic usage.

3) Patients with psychogenic involuntary movements, mental retardation, involuntary movements due to substance use with active mental illness and anxiety related movements.

\section{Study Design}

A descriptive comparative study with total sample of 60 patients. Sampling was done for convenience. Samples were patients who came with involuntary movements on an outpatient basis to the Departments of Neurology in Osmania General Hospital and Psychiatry in Institute of Mental Health were taken and divided into two groups

\section{Group 1}

Patients with involuntary movements due to psychotropic medication.

Male $15+$ Female 15 $=$ Total 30.

\section{Group 2}

Patients with involuntary movements of neurological disorders and not due to usage of psychotropic medication. Male $15+$ Female 15= Total 30.

\section{Statistical Methods}

- Statistical analysis was done using SPSS 22.0 version.

- Descriptive statistics were done for all the demographic and clinical variables and need assessments, and frequencies (percentage) were used for all parameters.

- Quantitative tests like chi-square test for calculating difference between the two groups for categorical variables.

- Comparison of two means for the scales among the two groups was done using Independent sample ' $t$ ' test.

- Spearman rho correlation test was used to assess the relationship between the adjustment and sociodemographic, clinical variables. Statistical significance was set at $\mathrm{p}$ value less than 0.05 .

\section{Tools}

1. Semi-Structured Intake Proforma.

2. Lawton-Brody Instrumental Activities of Daily Living Scale (IADL).(2)

Used to assess independent living skills of an individual and measures functional ability as well as declines and improvements over time validity: The validity of the Lawton
IADL was tested by determining its correlation with four scales that measured domains of functional status. All correlations were significant at the .01 or .05 level. Reliability: A Pearson correlation of 0.87 and 0.91 was obtained in two different studies. ICCs ranging from 0.90 to 0.94 for the IADL items were obtained. Very high six-month retest reliability of 0.88 (range, 0.80 - 0.99 ) has been reported for the IADL scale. The IADL also shows good inter-rater reliability between personnel from different disciplines.

3. Work and Social Adjustment Scale (WSAS).(3)

Work and social adjustment scale consists of 5 sections like ability to work, home management, social leisure activities, private leisure activities and close relationship with others. To rate a problem in each section and determine on the scale provided of how much problem impairs ability to carry out the activity. Rating as on Likert scale from 0 to 8.

4. Abnormal Involuntary Movement Scale (AIMS) (4)

The AIMS assesses abnormal involuntary movements in three body regions- Orofacial movements, rated on four separate items; Extremity movements, on two separate items; and Trunk movements, on one item. Each item is rated on a 5-point scale $(0-4)$ with instructions to rate the highest severity observed and to score movements that occur upon activation one less than those observed spontaneously. Three separate items score Global severity. The subject's awareness and incapacitation due to involuntary movements (each on a 5 -point scale). The AIMS as with many of the other multi-item scales is not a diagnostic instrument but usefully quantifies involuntary movements, giving ratings that can then be used with diagnostic criteria. The use of threshold scores or diagnostic cut-off points can result in heterogeneous groups in terms of regional distribution of dyskinesia.

5. General Health Questionnaire (GHQ 12).(5)

The General Health Questionnaire (GHQ) is widely used internationally and locally to measure mental health status, especially in detection of emotional disorders such as distress. The total possible score on GHQ-12 ranges from 0 to 36 and allows for means and distributions to be calculated, both for the global total as well as for the four sub-scales (somatic symptoms, anxiety/ insomnia, social dysfunction and severe depression). The GHQ-12 was commonly used, as its validity is well established internationally and locally. It was also used because of its popular use in student sample and young populations in the community.

\section{RESULTS}

- 60 patients divided into two groups.

Group 1- Patients with involuntary movements developed due to psychotropic medication.

Group 2- Patients with involuntary movements developed due to neurological disorders, not due to psychotropic medication usage.

- Each group matched in sex with patients taken in each group consisting of 15 each male and female patients with involuntary movement. 
Sociodemographic Data

\begin{tabular}{|c|c|c|c|c|}
\hline Variable & Group 1 n (\%) & Group 2 n (\%) & Test (Chi-Square) & Significance \\
\hline \multicolumn{5}{|c|}{ 1) Socioeconomic Status } \\
\hline Lower & $6(20.0)$ & $10(33.3)$ & \multirow{3}{*}{1.94} & \multirow{3}{*}{0.38} \\
\hline Middle & $23(76.7)$ & $18(60.0)$ & & \\
\hline Upper & $1(3.3)$ & $2(6.7)$ & & \\
\hline \multicolumn{5}{|c|}{ 2) Education } \\
\hline Illiterate & $11(36.7)$ & $13(43.3)$ & \multirow{5}{*}{2.60} & \multirow{5}{*}{0.63} \\
\hline Primary & $8(26.7)$ & $9(30.0)$ & & \\
\hline High School & $6(20.0)$ & 5 (16.7) & & \\
\hline Intermediate & $5(16.7)$ & $2(6.7)$ & & \\
\hline Graduate and above & $0(0.0)$ & $1(3.3)$ & & \\
\hline \multicolumn{5}{|c|}{ 3) Occupation } \\
\hline Unskilled & $4(13.3)$ & $5(16.7)$ & \multirow{4}{*}{1.37} & \multirow{4}{*}{0.72} \\
\hline Semiskilled & $11(36.7)$ & $14(46.7)$ & & \\
\hline Skilled & $7(23.3)$ & $4(13.3)$ & & \\
\hline Unemployed & $8(26.7)$ & $7(23.3)$ & & \\
\hline \multicolumn{5}{|c|}{ 4) Residence } \\
\hline Rural & $16(53.3)$ & $15(50.0)$ & \multirow{3}{*}{0.49} & \multirow{3}{*}{0.79} \\
\hline Semi Urban & $10(33.3)$ & $9(30.0)$ & & \\
\hline Urban & $4(13.3)$ & $6(20.0)$ & & \\
\hline \multicolumn{5}{|c|}{ 5) Marital Status } \\
\hline Unmarried & $6(20.0)$ & $2(6.7)$ & \multirow{3}{*}{2.86} & \multirow{3}{*}{0.41} \\
\hline Married and Living Together & $19(63.3)$ & $23(76.7)$ & & \\
\hline Separated or Divorced & $4(13.3)$ & $3(10.0)$ & & \\
\hline
\end{tabular}

\section{Diagnosis of Illness}

\begin{tabular}{|c|c|c|c|c|c|c|c|c|c|c|c|}
\hline & $\begin{array}{c}\text { SCHIZ } \\
\text { N (\%) }\end{array}$ & $\begin{array}{c}\text { BPAD } \\
\text { N (\%) }\end{array}$ & $\begin{array}{c}\text { PSY } \\
\text { NOS } \\
\text { N (\%) }\end{array}$ & PD N (\%) & $\begin{array}{c}\text { CVA } \\
\text { N (\%) }\end{array}$ & $\begin{array}{c}\text { HD } \\
\mathbf{N}(\%)\end{array}$ & $\begin{array}{c}\text { RD } \\
\text { N (\%) }\end{array}$ & $\begin{array}{c}\text { Tourette } \\
\text { N (\%) }\end{array}$ & $\begin{array}{c}\text { Others N } \\
\text { (\%) }\end{array}$ & $\begin{array}{c}\text { Chi- } \\
\text { Square }\end{array}$ & P Value \\
\hline Group 1 & $16(53.3)$ & $10(33.3)$ & $4(13.3)$ & $0(0.0)$ & $0(0.0)$ & $0(0.0)$ & $0(0.0)$ & $0(0.0)$ & $0(0.0)$ & 60.0 & $0.001^{* *}$ \\
\hline Group 2 & $0(0.0)$ & $0(0.0)$ & $0(0.0)$ & $15(50.0)$ & $3(10.0)$ & $2(6.7)$ & $1(3.3)$ & $3(10.0)$ & $6(20.0)$ & 60.0 \\
\hline
\end{tabular}

- $\quad$ Patients from Group 1 have Schizophrenia (53\%, N= 16), Bipolar affective disorder (BPAD) (33\%, N= 10) and Psychosis NOS $(13 \%, \mathrm{~N}=4)$.

- $\quad$ Group 2 have Parkinson's disease (PD) (50\%, N= 15) followed by others $(20 \%, \mathrm{~N}=6)$; Tourette's disease (10\%, $\mathrm{N}=3)$; Cerebrovascular accident (CVA) (10\%, N= 3); Huntington's disease (HD) (7\%, N=2) and Rheumatic disease (RD) (3\%, N=1).

- $\quad$ There is statistically significant difference between two groups ( $\mathrm{p}$ value $=0.001$ ).

Type of Involuntary Movement

\begin{tabular}{|c|c|c|c|c|c|c|c|c|c|}
\hline Groups & Tremor & Akathisia & Dystonia & T D & Chorea & Athetosis & Tics & Chi-Square & P Value \\
\hline Group 1 & $12(40.0)$ & $4(13.3)$ & $9(30.0)$ & $5(16.7)$ & $0(0.0)$ & $0(0.0)$ & $0(0.0)$ & & \\
\hline Group 2 & $15(50.0)$ & $0(0.0)$ & $1(3.3)$ & $2(6.7)$ & $6(20.0)$ & $2(6.7)$ & $4(13.3)$ & 24.0 & $0.001^{* *}$ \\
\hline Total N (\%) & $\mathbf{2 7 ( 4 5 . 0 )}$ & $\mathbf{4 ( 6 . 7 )}$ & $\mathbf{1 0 ( 1 6 . 7 )}$ & $\mathbf{7 ( 1 1 . 7 )}$ & $\mathbf{6 ( 1 0 . 0 )}$ & $\mathbf{2 ( 3 . 3 )}$ & $\mathbf{4 ( 6 . 7 )}$ & & \\
\hline
\end{tabular}

Tremor consists of major involuntary movement in Group 1 and 2 (40\% and 50\%, N= 12 and 15 respectively) with overall of $45 \%(\mathrm{~N}=27)$.

Patients in Group 1 having involuntary movements other than tremor were Dystonia $(30 \%, \mathrm{~N}=9)$, Tardive dyskinesia $(17 \%, \mathrm{~N}=$ 5) and Akathisia (13\%, N=4). Patients in Group 2 having Chorea (20\%, N=6), Tics (13\%, N= 4), Athetosis (7\%, N=2), Tardive dyskinesia $(7 \%, \mathrm{~N}=2)$ and Dystonia $(3 \%, \mathrm{~N}=1)$. There is a significant statistical difference with $\mathrm{p}$ value of 0.001 .

\section{Duration of Involuntary Movements}

\begin{tabular}{|c|c|c|c|c|c|}
\hline Item & Groups & Mean (S. D.) & Median & Chi-Square & P value \\
\hline Duration of Involuntary & Group 1 & $80.0(148.2)$ & 30.0 & & \\
Movements in Days & Group 2 & $156.2(103.6)$ & 135.0 & -2.31 & $0.03^{*}$ \\
\hline
\end{tabular}


Mean duration of involuntary movements in days is in Group 1 and Group 2 were 80 and 156, which shows significantly high in Group 2 with statistical significance between two groups as per duration of involuntary movements were concerned ( $p$ value $=0.025$ ).

\section{Comparison of Different Scales}

\begin{tabular}{|l|l|c|c|c|c|}
\hline Items & Groups & Mean (S.D.) & T value & 95\% C.I. & P value \\
\hline \multirow{2}{*}{ IADL } & Group 1 & $2.70(1.50)$ & & -0.81 to & \\
& Group 2 & $2.60(2.00)$ & 0.22 & 1.00 & 0.83 \\
\hline \multirow{2}{*}{ WSAS } & Group 1 & $28.00(8.40)$ & & -2.52 to & \\
& Group 2 & $26.00(8.90)$ & 0.88 & 6.50 & 0.38 \\
\hline \multirow{2}{*}{ GHQ } & Group 1 & $25.00(4.80)$ & & -1.36 to & \\
& Group 2 & $23.00(5.60)$ & 0.99 & 4.00 & 0.33 \\
\hline \multirow{2}{*}{ AIMS } & Group 1 & $19.40(5.90)$ & & 1.60 to & \\
& Group 2 & $15.00(5.20)$ & 3.10 & 7.30 & $0.003^{* *}$ \\
\hline
\end{tabular}

- Mean Instrumental activities of daily living (IADL) scale score of Group 1 is 2.70 and Group 2 is 2.60. IADL scores ranges from 0 to 8 , low scores suggestive of less function and dependent. Hence, both groups had less function and dependent, but statistically no significant difference among both groups ( $\mathrm{p}$ value $=0.83$ ).

- Mean work and social adjustment scale (WSAS) score of Group 1 is 28 and Group 2 is 26. High scores are suggestive of functional impairment. WSAS scores ranges from 0 to 40 , scores 10 to 20 was mild-to-moderate impairment, more than 20 was severe-to-worse impairment. Thus, scores of Group 1 and 2 fall into severe-to-worse problem in adjustment to work and social activities, but statistically no significant difference among both groups ( $\mathrm{p}$ value $=0.38$ ).

- Mean general health questionnaire (GHQ-12) scores of the Group 1 and 2 are 25 and 23. GHQ 12 scores ranges from 0 to 36 , categorised as 0 to 9 is normal, 10 to 18 is mild problem, 19 to 27 is moderate problem and above
27 is severe problem. Hence, scores of both groups fall into moderate problem category of psychological disturbance, but statistically no significant difference among both groups ( $\mathrm{p}$ value 0.33 ).

- Mean abnormal involuntary movement scale (AIMS) score of Group 1 and 2 are 19.4 and 15.0. Scores of AIMS ranges from 0 to 40 , categorised as 0 to 8 is none, 9 to 16 is minimal, 17 to 24 is mild, 25 to 32 is moderate and above 32 is severe. So patients of both groups had severity of involuntary movements in mild category; however, mean score was high in Group 1 than group 2 with statistically highly significant difference between both groups ( $p$ value $=0.003$ )

\section{Comparison of Components of Aims}

\begin{tabular}{|c|c|c|c|c|}
\hline & Group & Mean (S.D.) & $\begin{array}{c}\text { Chi- } \\
\text { Square }\end{array}$ & $\begin{array}{c}P \\
\text { value }\end{array}$ \\
\hline \multirow{2}{*}{$\begin{array}{l}\text { Facial and Oral } \\
\text { movements }\end{array}$} & Group 1 & \multirow{2}{*}{$\begin{array}{l}7.93(4.30) \\
4.30(4.00)\end{array}$} & & \\
\hline & Group 2 & & 3.40 & $0.001^{* x}$ \\
\hline \multirow{2}{*}{$\begin{array}{l}\text { Extremity } \\
\text { movements }\end{array}$} & Group 1 & $1.70(2.23)$ & & \\
\hline & Group 2 & $1.50(1.93)$ & 3.72 & 0.71 \\
\hline \multirow{2}{*}{$\begin{array}{c}\text { Trunk } \\
\text { movements }\end{array}$} & Group 1 & \multirow{2}{*}{$\begin{array}{l}1.30(1.44) \\
0.83(1.32)\end{array}$} & & \\
\hline & Group 2 & & 1.31 & 0.20 \\
\hline \multirow{2}{*}{$\begin{array}{c}\text { Global } \\
\text { judgements }\end{array}$} & Group 1 & \multirow{2}{*}{$\begin{array}{l}8.30(1.71) \\
8.27(2.18)\end{array}$} & & \\
\hline & Group 2 & & 0.07 & 0.95 \\
\hline \multirow{2}{*}{$\begin{array}{l}\text { AIMS Total } \\
\text { score }\end{array}$} & Group 1 & \multirow{2}{*}{$\begin{array}{l}19.43(5.88) \\
15.00(5.23)\end{array}$} & & \\
\hline & Group 2 & & 3.10 & $0.005^{*}$ \\
\hline
\end{tabular}

- Mean score of facial and oral movements in AIMS is high in Group 1 (7.93) than Group 2 (4.30), which is highly significant ( $p$ value 0.001 ) and also as previously mentioned showing high mean AIMS total score in Group 1 compared to Group 2 with statistically high significance ( $p$ value 0.003 ).

\section{Correlations}

\begin{tabular}{|c|c|c|c|c|c|c|}
\hline & & AIMS Score & GHQ Score & IADL Score & WSAS Score & Duration of Movement \\
\hline \multirow{2}{*}{ AIMS score } & $\mathrm{R}$ & 1.000 & $.455^{* *}$ & -.222 & $.479^{* *}$ & $-.514^{* *}$ \\
\cline { 2 - 7 } & $\mathrm{P}$ &. & .001 & .089 & .001 & .001 \\
\hline \multirow{2}{*}{ GHQ score } & $\mathrm{R}$ & $.455^{* *}$ & 1.000 & $-.387^{* *}$ & $.558^{* *}$ &. $.558^{* *}$ \\
\cline { 2 - 7 } & $\mathrm{P}$ & .001 &. & .002 & .001 & .001 \\
\hline \multirow{2}{*}{ IADL score } & $\mathrm{R}$ & -.222 & $-.387^{* *}$ & 1.000 & $-.729^{* *}$ & .196 \\
\cline { 2 - 7 } & $\mathrm{P}$ & .089 & .002 &. & .001 & .134 \\
\hline \multirow{2}{*}{ WSAS score } & $\mathrm{R}$ & $.479^{* *}$ & $.558^{* *}$ & $-.729^{* *}$ & 1.000 &. $.459^{* *}$ \\
\hline \multirow{2}{*}{$\begin{array}{c}\text { Duration of } \\
\text { movement }\end{array}$} & $\mathrm{P}$ & .001 & .001 & .001 &. & .001 \\
\cline { 2 - 7 } & $\mathrm{R}$ & $-.514^{* *}$ & $-.558^{* *}$ & .196 & $-.459^{* *}$ & .000 \\
\hline
\end{tabular}

- $\quad$ AIMS scores has strong positive linear relationship with scores of GHQ ( $r=0.46)$ and WSAS $(r=0.48)$ with $\mathrm{p}$ value of 0.001 for all. But has negative linear relationship with duration of involuntary movement $(\mathrm{r}=-0.51, \mathrm{p}=0.001)$. There was no linear relationship between AIMS scores and IADL scores ( $\mathrm{r}=-0.22$, $\mathrm{p}=0.90)$.

- GHQ scores has strong positive linear relationship with scores of AIMS ( $r=0.45)$ and WSAS $(r=0.56)$ with $p$ value of 0.001 . Negative linear relationship with scores of IADL ( $r=-0.39, \mathrm{p}=0.002)$ and duration of involuntary movement $(\mathrm{r}=-0.56, \mathrm{p}=0.001)$.

- IADL scores has negative linear relationship with scores of GHQ ( $\mathrm{r}=-0.39, \mathrm{p}=0.002$ ) and WSAS ( $\mathrm{r}=-0.73$, $\mathrm{p}=0.001$ ); has no linear relationship with AIMS scores and duration of involuntary movement.

- WSAS scores has strong positive linear relationship with scores of AIMS ( $\mathrm{r}=0.48)$, GHQ $(\mathrm{r}=0.56)$. Negative linear relationship with scores of IADL $(r=-0.73)$ and duration 
of involuntary movement $(\mathrm{r}=-0.46)$. $\mathrm{P}$ value of 0.001 for all.

- Duration of involuntary movement has negative linear relationship with scores of AIMS ( $\mathrm{r}=-0.51)$, GHQ ( $\mathrm{r}=$ $0.56)$ and WSAS ( $r=-0.46$ ) with $\mathrm{p}$ value of 0.001 for all, but no linear relation with scores of IADL.

\section{DISCUSSION}

- Most of patients with involuntary movements belong to middle class socioeconomic status, were illiterates or had primary school education, were semi-skilled workers by occupation and were mostly hailing from rural areas.

- High proportion of patients $(70 \%, \mathrm{~N}=42)$ from both the groups were married and were living with their spouse.

- $\quad$ Patients from Group 1 having diagnoses in percentages are schizophrenia $(53 \%, \mathrm{~N}=16)$, bipolar affective disorder (BPAD) $(33 \%, \mathrm{~N}=10)$ and psychosis NOS $(13 \%$, $\mathrm{N}=4$ ).

- Patients from Group 2 having diagnoses in percentages are Parkinson's disease (PD) $(50 \%, \mathrm{~N}=15)$ followed by others $(20 \%, \mathrm{~N}=6)$, Tourette's disease $(10 \%, \mathrm{~N}=3)$, Cerebrovascular accident (CVA) $(10 \%, \quad \mathrm{~N}=3)$, Huntington's disease (HD) $(7 \%, \mathrm{~N}=2)$ and Rheumatic disease (RD) (3\%, $\mathrm{N}=1)$.

- Tremor consists of major involuntary movement in Group 1 and $2 \quad(40 \%$ and $50 \%, \mathrm{~N}=12$ and 15 respectively) with overall of $45 \%(\mathrm{~N}=27)$. Patients in Group 1 having involuntary movements other than tremor were Dystonia (30\%, $\mathrm{N}=9$ ), Tardive Dyskinesia $(17 \%, \mathrm{~N}=5)$ and Akathisia $(13 \%, \mathrm{~N}=4)$. Patients in Group 2 having Chorea (20\%, N=6), Tics (13\%, N=4) and Athetosis $(7 \%, \mathrm{~N}=2)$.

- Duration of involuntary movements was higher in Group 2 compared to Group 1.

- According to the prevalence studies, a study of heredity of essential tremor: Tremor is the most common movement disorder; PD is $2^{\text {nd }}$ and Dystonia being $3^{\text {rd }}$ common. Deuschl G, Bain P, Brin M et al 1998.(6) In this study also found that tremor was more followed by Parkinsonian tremor and dystonia.

- Duration of involuntary movements-

- In the present study, mean duration in Group 1 was 80 days and Group 2 was 156 days.

- Duration of involuntary movements was less in those developed due to psychotropic medication than those who had involuntary movements in neurological diseases.

\section{Instrumental Activities of Daily Living Scale-}

- In this study, mean instrumental activities of daily living scale score of Group 1 is 2.70 and Group 2 is 2.60. IADL scores ranges from 0 to 8 , low scores in two Groups are suggestive of less function and dependence.

- Hence, both groups had less function and dependence with their involuntary movements, but no significant difference among both groups. These study findings correlates with study on PD by Gerry Mshana et al (2011).(7)

\section{Work and Social Adjustment Scale-}

- In the present study, the mean for patients of Group 1 is 28 and Group 2 is 26 . High scores in both groups are suggestive of functional impairment with their involuntary movements.

- Scores of Group 1 and 2, fall into severe-to-worse problem in adjustment to work and social activities, but no significant difference among both groups.

- These study findings correlates with study on PD by Gerry Mshana et al (2011).(7)

- Working is correlated with positive outcomes in social functioning, symptom levels, quality of life and selfesteem, but a clear causal relationship has not been established.(8)

\section{General Health Questionnaire-}

- In this study found that mean General health questionnaire (GHQ 12) scores of the Group 1 and 2 are 25 and 23.

- Scores of both groups fell into moderate problem category of psychological disturbance, so they were with psychological problems with their involuntary movements, but no significant difference among both groups.

- These study findings correlated with study by Manju Mathew MD et al (2005),(9) Link and Phelan (2001),(10) Nicholls et al (2003), Piot (2001), Weiss and Ramakrishna (2001).(11)

\section{Abnormal Involuntary Movement Scale-}

- In the present study, mean abnormal involuntary movement scale scores of Group 1 and 2 are 19.4 and 15.0.

- Patients of both groups had severity of involuntary movements in mild category; however, mean score was high in Group 1 than Group 2 with highly significant difference between both groups. Thus, involuntary movements were severe in patients with involuntary movements due to psychotropic medication, mainly due to acute psychotropic induced involuntary movements like dystonia, akathisia and tremor were severe in intensity.

- Mean score of facial and oral movements in AIMS is high in Group 1 (7.93) than Group 2 (4.30), which is highly significant. This was mainly due to involuntary movements in Group 1 like Dystonia affects predominantly facial and oral areas.

- $\quad$ AIMS scores has strong positive linear relationship with scores of GHQ and WSA, as with increasing AIMS scores also increases scores of GHQ and WSAS.

- But has negative linear relationship duration of involuntary movement, so AIMS scores were high in patients having less duration of involuntary movements. With increasing severity of involuntary movements, patients were with more psychological disturbances and adjustment to work and social situations.

- $\quad$ Both personal effects and negative public health impact are surprisingly similar for a wide range of chronic stigmatised conditions. The effects on the affected individual include psychological stress, depression and other psychiatric morbidity, fear, marital and relationship problems, other social participation 
restrictions such as loss of employment or reduced employment opportunities and reduced education opportunities, increased (risk of) disability and advanced disease. This is also in concordance with study by Van Brakel et al.(12)

\section{Summary}

- Most of the patients with involuntary movements belong to middle class socio-economic status.

- Most of the patients were illiterates or had primary school education.

- Most of the patients from both groups were semi-skilled workers by occupation.

- $\quad$ Patients in this study from both the groups were mostly hailing from rural areas.

- High proportion of patients (70\%) from both the groups were married and were living with their spouse.

- $\quad$ Patients from Group 1 having diagnoses in percentages are Schizophrenia (53\%), Bipolar affective disorder (BPAD) (33\%) and Psychosis NOS (13\%).

- $\quad$ Patients from Group 2 having diagnoses in percentages are Parkinson's disease (PD) (50\%) followed by others $(20 \%)$, Tourette's disease $(10 \%)$, Cerebrovascular accident (CVA) (10\%), Huntington's disease (HD) (7\%) and Rheumatic disease (RD) (3\%).

- Tremor consists of major involuntary movement in Group 1 and 2 (40\% and 50\% respectively) with overall of $45 \%$. Patients in Group 1 having involuntary movements other than tremor were Dystonia (30\%), Tardive Dyskinesia (17\%) and Akathisia (13\%). Patients in Group 2 were having Chorea (20\%), Tics (13\%) and Athetosis (7\%).

- Duration of involuntary movements was higher in Group 2 compared to Group 1.

- In instrumental activities of daily living scale two groups scored low, suggestive of less function and dependency.

- In work and social adjustment scale, high scores in both the groups were suggestive of functional impairment with their involuntary movements.

- In General health questionnaire scores of both groups fall into moderate problem category of psychological disturbance, so they were with psychological problems with their involuntary movements.

- In Abnormal involuntary movement scale, patients of both groups had severity of involuntary movements in mild category; however, score was high in Group 1 than Group 2 and score of facial and oral movements in AIMS was high in Group 1 than Group 2.

- Severity of involuntary movements associated with psychological disturbances, and problems in adjustment to work and social situations.

\section{CONCLUSION}

- The patients with involuntary movements have less functioning and they had problems in adjusting to work and social situations, and had psychological disturbances.
- There is no difference among the two groups regarding problems in adjustment, both groups have adjustment problems.

- Adjustment problems were strongly correlating with severity of involuntary movements. Thus, adjustment problems depend more on severity of involuntary movements than aetiology.

\section{Limitations of the Study}

1. Small sample size and sample was done for convenience.

2. Cross-sectional study.

3. This study was done in two tertiary care hospitals, where patients with severe involuntary movements were included. This cannot be generalised to general population.

4. Scales used in the study were not standardised to Indian population.

\section{REFERENCES}

[1] Tasman A, Kay J, Lieberman JA, et al. Medicationinduced movement disorders. Psychiatry. $3^{\text {rd }}$ edn. John Wiley \& Sons Ltd., 2008:1773-90.

[2] Lawton MP, Brody EM. Assessment of older people: self-maintaining and instrumental activities of daily living. Gerontologist 1969;9(3):179-86.

[3] Mundt JC, Marks IM, Shear MK, et al. The Work and Social Adjustment Scale: a simple measure of impairment in functioning. The British Journal of Psychiatry 2002;180(5):461-4.

[4] Guy W. ECDEU Assessment Manual for Psychopharmacology. Revised edn. Rockville, Washington DC: US Department of Health, Education, and Welfare 1976.

[5] Goldberg DP, Hillier VF. A scaled version of the General Health Questionnaire. Psychological Medicine 1979;9(1):139-45.

[6] Deuschl G, Bain P, Brin M. Consensus statement of the Movement Disorder Society on Tremor. Ad Hoc Scientific Committee Mov Disord 1998;13(Suppl 3):223.

[7] Mshana G, Dotchin CL, Walker RW. We call it the shaking illness': perceptions and experiences of Parkinson's disease in rural northern Tanzania, BMC Public Health 2011;11:219.

[8] Marwaha S, Johnson S. Schizophrenia and employment - a review. Social Psychiatry and Psychiatric Epidemiology 2004;39(5):337-49.

[9] Mathews M, Gratz S, Adetunji B, et al. AntipsychoticInduced Movement Disorders. Evaluation and treatment. Psychiatry (Edgmont) 2005;2(3):36-41.

[10] Link BG, Phelan JC. Conceptualizing stigma. Annual Review of Sociology 2001;27:363-85.

[11] Weiss MG, Ramakrishna J. Stigma Interventions and Research for International Health. Bethesda, Maryland, USA: 2001.

[12] Stevelink SAM, van Brakel WH. The cross-cultural equivalence of participation instruments: a systematic review. Disavil Rehabil 2013;35(15):1256-68. 